\title{
Self-Release of Ski Bindings: A Sex Comparison
}

\author{
Markus Posch, Gerhard Ruedl, Robert Eberle, and Martin Burtscher
}

\begin{abstract}
Background: Among recreational skiers, ACL injury risk is about three times greater in females compared to males and female skiers suffering from ACL injury reported about $20 \%$ points more frequently a failure of binding to release compared to male skiers with an ACL injury. Performing a daily self-release test of ski bindings, however, can prevent skiing-related injuries of the lower extremity.

Aim: To evaluate to what extent uninjured male and female skiers are able to selfrelease their ski bindings which were recently adjusted to the ISO 11088 standard.

Methods: A total of 15 male and 15 female healthy and physically active young adults with a mean age of $23.0 \pm 1.7$ years and without any previous injury of the lower extremities participated in this study. Subjects had to perform an isometric leg test and the self-release test of ski bindings with both legs on a Kistler force plate. For each attempt to release the binding, torques calculated via the force plate were normalized to torques calculated by a binding adjustment system (Relative Release Torques-RRT) and represented by percentage values.

Results: Sexes significantly differ regarding body mass and BMI, but not regarding relative maximum isometric leg strength. Eleven out of the 15 male subjects $(73 \%)$ and three out of the 15 female (20\%) subjects released their ski bindings at least once with both legs. Regarding a total of 90 self-release trials among each sex ( 3 trials $\times 2$ legs $\times 15$ subjects), failure of binding release was significantly higher among female compared to male trials ( 84 vs. $54 \%, p<0.01$ ). The mean relative release torques (RRT) of the 76 female trials of failure of binding release were significantly lower compared to the 49 male trials of failure of binding release $(40.9 \pm 20.2$ vs. $50.6 \pm 20.1 \%, p=0.009)$.

Conclusion: Three times more females than males were unable to self-release their ski bindings although their bindings were correctly adjusted according to the ISO 11088 standard for binding setting values. In addition, females reached about $20 \%$ lower RRT values within failure of binding release trials although males and females did not differ with regard to relative isometric leg strength.
\end{abstract}

M. Posch • G. Ruedl $(\bowtie) \bullet$ R. Eberle $\bullet$ M. Burtscher Department of Sport Science, University of Innsbruck, Fürstenweg 185, 6020 Innsbruck, Austria

e-mail: gerhard.ruedl@uibk.ac.at 
Keywords Ski binding release - Self-release test $\bullet$ Alpine skiing Prevention - Knee injury

\section{Introduction}

Recreational alpine skiing is one of the most popular winter sports annually enjoyed by several 100 million skiers worldwide [1, 2]. Despite the large number of skiers, the currently calculated injury rate in Austria is less than one injury per 1000 skier days [3]. The knee joint represents the most commonly injured body part accounting for about one-third of all injuries in recreational skiers, however with a distinctive difference between sexes [3-5]. Female recreational skiers have twice the knee injury prevalence of male skiers and the ACL injury risk is three times greater in female skiers [4-6]. This sex difference of knee injuries among recreational alpine skiers may be partly related to hormonal, anatomical, and/or neuromuscular risk factors which distinguish females from males [7, 8]. Another decisive sex difference among knee-injured skiers concerns the amount of failure of binding to release at the moment of accident [9-12]. For instance, a total of 55-67\% male skiers reported a failure of the ski bindings to release compared to $74-88 \%$ of female skiers suffering from an ACL injury [9-12]. This difference in binding non-releases percentages occurred even though there was no difference in the date of last binding adjustment [11], whether the bindings were adjusted correctly [13], or self-reported types of falling [11, 12]. In a very recent study among a cohort of about 500 male and female recreational skiers suffering from an ACL injury, Ruedl et al. [12] showed that binding release was independently associated with forward falling with rotation. This so-called forward twisting fall [12] corresponds well with the self-release test of ski bindings where skiers try to release their bindings by an inward twist of their leg [14]. Previous studies by Ekeland et al. [15] and Jørgensen et al. [16] found that performing daily the self-release test of ski bindings can prevent skiing-related injuries of the lower extremity. Keeping in mind that female skiers with an ACL injury reported about $20 \%$ points more failures of binding to release compared to male skiers with an ACL injury, the aim of this study was to evaluate to what extent uninjured male and female skiers are able to self-release their ski bindings that were recently adjusted according to the ISO 11088 standard for binding setting values. As the ISO 11088 standard for binding setting values does not consider sex-specific differences, we hypothesized that there are no differences between male and female skiers performing the selfrelease test. 


\section{Material and Method}

\subsection{Subjects}

A total of 15 male and 15 female healthy and physically active young adults without previous injury of the lower extremities were asked to participate in this study. Most participants were students from the Department of Sport Science in Innsbruck/ Austria with an advanced skiing skill level.

The study was performed in conformity with the ethical standards of the 2008 Declaration of Helsinki. Informed written consent was obtained from all subjects prior to the beginning of this research. In addition, the study was approved by the Institutional Review Board.

\subsection{Study Protocol}

After subjects performed a standardized warming up, maximal isometric leg strength of both legs were tested. Then subjects had to perform three trials with each leg to release their bindings adjusted according to the ISO 11088 standard.

\subsection{Ski Binding Adjustment}

Each subject used his/her own skies and ski boots. The day before the tests took place the skies and ski boots were taken to a ski rental shop where the ski bindings were correctly adjusted according to the ISO 11088 standard using a Wintersteiger Speedtronic adjustment system. Release values of the bindings according to the ISO 11088 standard are determined using individual age, height, weight, skiing type, and sole length of ski boots. In addition, skiers have to differentiate between skiing speed (slow to moderate vs. fast), terrain (gentle to moderate vs. steep), and skiing style (cautious vs. aggressive) to classify themselves into one out of three skiing types. The Wintersteiger Speedtronic adjustment system then calculated the required release torques for the toe and heel piece of the ski binding.

\subsection{Isometric Leg Strength Test}

Prior to the isometric leg strength test all participants had to do a 7 min warming-up programme on a stationary cycle ergometer. Regarding the determination of leg dominance, subjects were asked which leg they would prefer to kick a ball. According to a study by Raschner et al. [17], participants performed three one-leg isometric leg extensions on each leg. The greater trochanter, lateral intercondylar 
notch, and lateral malleolus were used as landmarks to ensure that a knee angle of $100^{\circ}$ was reached $\left(180^{\circ}=\right.$ fully extended knee). The calculated strength parameters were the mean absolute leg force and the mean relative leg force which was got when dividing the absolute leg force by body weight [17].

\subsection{Self-Release Test}

For the self-release test of the ski binding a wooden plate was fixed on a Kistler force plate (Fig. 1). Then, the ski was fixed with metal bars on the wooden plate in a way that the participants were not able to move their skis neither in vertical nor in horizontal direction. The fixation of the ski was necessary in order to make the measured values of self-release trials comparable with the testing results of the Wintersteiger Speedtronic device. The subjects were given detailed instructions and a demonstration by the first author how to perform the self-release test by simultaneously avoiding a rotation of the hips and/or valgus position of the knee. Subjects were not allowed to practice self-releases before the testing started. In order to provide a ski-specific position all participants were told to wear both ski boots and to use their ski poles (Fig. 1). Participants tried to release the toe piece of their ski bindings by an inward twist of their foot and leg, but without an inward movement of the knee. Each leg was tested three times. For each attempt to release the binding, torques calculated via the force plate were normalized to torques calculated by the Wintersteiger binding adjustment system (Relative Release Torques_-RRT) and represented by percentage values.
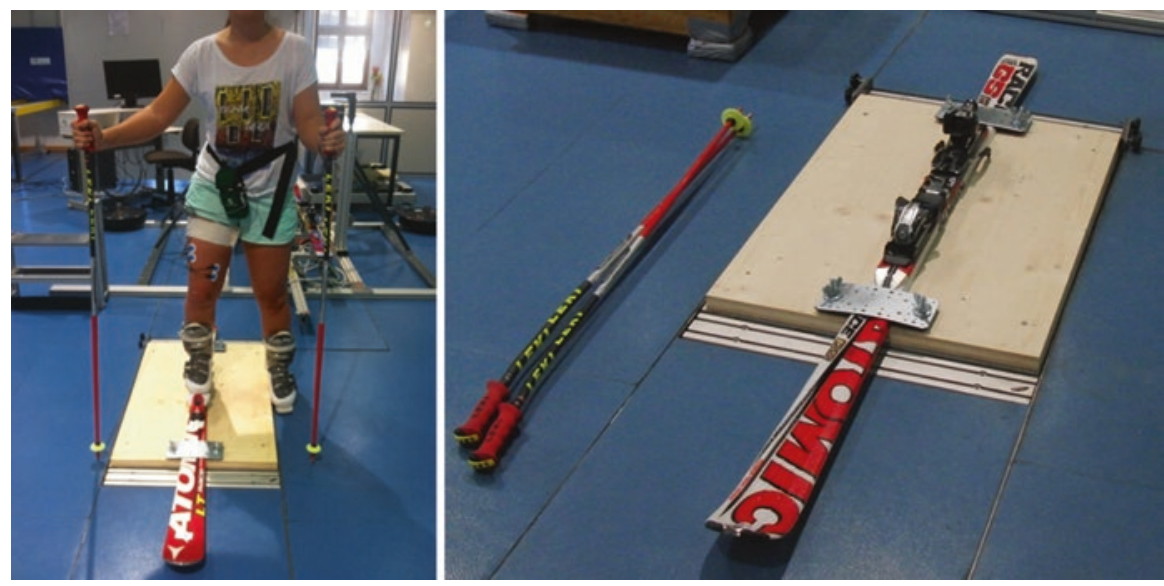

Fig. 1 Self-release test on a Kistler force plate 


\section{Statistics}

Data are presented as means, absolute, and relative frequencies. Differences in mean age, height, weight, BMI, and dominant leg strength with regard to sex were evaluated by independent $t$-tests and Mann-Whitney $U$-tests. Differences in ski binding release frequencies were evaluated by $\chi^{2}$ tests. Sex-specific differences in isometric leg strength, ski binding release torques were investigated by independent t-tests and Mann-Whitney $U$-tests. Statistical analyses were performed by the use of SPSS 23.0. All $P$ values were two-tailed and values less than 0.05 were considered to indicate statistical significance.

\section{Results}

A total of 15 males and 15 females with a mean age of $23.0 \pm 1.7$ (range: $20-28$ ) years participated in this study. With regard to leg dominance, 29 subjects reported dominance of their right leg and one subject of his left leg.

The sex comparison in Table 1 shows significant differences regarding age, height, weight, BMI, but not concerning the relative isometric leg strength of both legs.

Eleven out of the 15 male subjects (73\%) and three of the 15 female subjects (20\%) released their ski bindings at least once with both legs. Regarding the total of 90 trials of the self-release tests among each sex $(3$ trials $\times 2$ legs $\times 15$ subjects $)$, failure of binding release was significantly higher among female compared to male trials (84 vs. $54 \%, p<0.01)$.

Mean relative release torques of the 14 female trials of binding release did not significantly differ compared to the 41 male trials of binding release $(99.0 \pm 19.4 \mathrm{vs}$. $88.0 \pm 26.0 \%, p=0.132$ ).

Mean relative release torques of the 76 female trials of failure of binding release were significantly lower compared to the 49 male trials of failure of binding release $(40.9 \pm 20.2$ vs. $50.6 \pm 20.1 \%, p=0.009)$.

Table 1 Baseline characteristics of participants

\begin{tabular}{l|l|l|l}
\hline & Males $(n=15)$ & $\begin{array}{l}\text { Females } \\
(n=15)\end{array}$ & $p$ value \\
\hline Age $[$ years] & $23.6 \pm 1.1$ & $22.4 \pm 2.0$ & 0.017 \\
\hline Height $[\mathrm{cm}]$ & $180 \pm 0.1$ & $167 \pm 0.1$ & $<0.001$ \\
\hline Weight $[\mathrm{kg}]$ & $77.0 \pm 4.4$ & $60.2 \pm 5.6$ & $<0.001$ \\
\hline BMI $\left[\mathrm{kg} / \mathrm{m}^{2}\right]$ & $23.9 \pm 1.9$ & $21.6 \pm 1.4$ & 0.001 \\
\hline $\begin{array}{l}\text { Relative isometric strength of the } \\
\text { dominant leg }[\mathrm{N} / \mathrm{kg}]\end{array}$ & $16.4 \pm 2.5$ & $15.0 \pm 2.1$ & 0.107 \\
\hline $\begin{array}{l}\text { Relative isometric strength of the } \\
\text { non-dominant leg }[\mathrm{N} / \mathrm{kg}]\end{array}$ & $15.7 \pm 2.2$ & $14.4 \pm 2.0$ & 0.094 \\
\hline
\end{tabular}

Data are mean values $\pm \mathrm{SD}$ 


\section{Discussion}

The aim of the present study was to evaluate to what extent uninjured male and female skiers are able to self-release their ski bindings that were recently adjusted according to the ISO 11088 standard for binding setting values. The main finding was that significantly more females were not able to self-release their ski bindings compared to males.

In our tests, $84 \%$ of female trials and $54 \%$ of male trials showed a failure of selfrelease of their ski bindings. These sex-specific values seem in line with findings observed among ACL-injured recreational skiers where $74-88 \%$ of female skiers compared to 55-67\% male skiers reported a failure of binding to release [9-12]. This conformity might be somewhat surprising as the self-release test was performed in a stationary laboratory setting in contrast to the self-reported amount of failure of binding release during skiing on the slope leading to an ACL injury. However, it may become understandable considering the findings by LaPorte et al. [10] who showed that a total of $44 \%$ of lower leg injuries (50\% of all tibia fractures, $44 \%$ of all MCL injuries, $47 \%$ of all complex knee sprains, and $43 \%$ of all ACL injuries) occurred at low speed or in a stationary position indicating the potential problem of ski binding release at low speed.

Relative release torques (RRT) of female and male trials of failure of binding release were about 41 and $51 \%$, respectively, indicating a huge difference to the recommended binding setting values. In a field experiment, Scher and Mote [18] analysed forces among a cohort of 12 recreational skiers (two females, ten males) during skiing by using two six-load component dynamometers which were attached under the toe and the heel binding of the left ski. They found that the ASTM (American Society for Testing and Materials) recommended release settings were significantly higher than the forces required to ski normally on varied terrain from hard snow to soft spring snow for ten of the 12 skiers [18]. With regard to the lateral release setting at the toe, ten of the subjects skied within $67 \%$ of the current settings and could have lowered this setting by $33 \%$ without signalling for inadvertent release [18]. In addition, for inexperienced, lightweight skiers, the release setting at the toe could have been lowered by $38 \%$. Interestingly, the only subject who fell two times and released from the ski was a female beginner skier whose measured minimum retention setting at the toe was found to be $61 \%$ of the ASTM recommended setting [18]. Scher and Mote [18] concluded from their results that forces generated during skiing depend more on a skiing style variable than on anthropometrical parameters and that, therefore, binding standards that depend on weight, height, and age cannot predict accurately the minimum retention settings for individual skiers. According to the ISO 11088 standard for binding values, skiers have to differentiate between skiing speed (slow to moderate vs. fast), terrain (gentle to moderate vs. steep), and skiing style (cautious vs. aggressive) to classify themselves into one out of three skiing types. Studies, however, found that female skiers are skiing on average at significant lower speeds compared to male skiers $[13,19]$ and that females, less skilled and cautious skiers perceived their actual speed as fast, moderate, and slow when skiing up to $10 \mathrm{~km} / \mathrm{h}$ significantly slower compared males, more skilled 
skiers, and risky skiers [20]. As the ISO 11088 standard for binding setting values does not consider any sex-specific factor so far and to get more insight in needed retention settings of male and female recreational skiers, we would strongly recommend replicating the study design by Scher and Mote [18], however, aiming at comparing potential differences between males and females.

The observed RRT difference of about $20 \%$ between male and female trials of failure of binding release might be also considered when discussing the implementation of a sex factor within the ISO 11088 standard. In previous years, a lower binding setting among female skiers has been discussed by LaPorte et al. [21]. In a case-control study, they found that lower binding release values in female skiers set $15 \%$ lower than those recommended by the ISO 11088 standard would clearly reduce knee injuries in these persons. No increase in injuries from inadvertent binding release through reduced binding settings has been found [21]. However, these findings mean an association, and not definitely "cause and effect" relationship, because another study at the same time showed a decrease in ACL injury risk without reducing binding settings [22] which might be due to the introduction of the short and shaped carving skis at this time [11]. Interestingly, the ISO 11088 standard accepts a deviation of $15 \%$ between the measured release moment ("reference moment") determined according to the setting tables in ISO 8061 and ski binding settings may also be lowered by the same magnitude upon request of the skier [23]. However, this fact is generally unknown in the overall skier population, but could represent a potential preventive measure, especially for female recreational skiers.

A study by Werner and Willis [14] found that muscle strength is highly correlated with the ability to release the binding in a self-release test. Assume that a male and a female skier of equal age, height, weight, and ski boot sole length classified themselves as type-3 skier (fast speed, steep terrain, aggressive style). They both would get the same binding setting values without considering sex. With regard to the equal weight of the male and female skier in the mentioned example, it has to be considered that the weight-to-strength ratio is negatively influenced by the higher fat mass in females [24] may be partly explaining the sex difference within the lack of binding release among ACL-injured recreational skiers due to less muscular strength among females. Participants of the present study were young healthy and physically active males and females. Although sexes significantly differ regarding body mass and BMI, no significant differences were detected within relative maximum isometric leg strength when normalized by body weight. Therefore, one would assume that both sexes are able to self-release their bindings to the same amount.

As performing the self-release test seems to prevent skiing injuries [15, 16], male and female skiers should be able to self-release their ski bindings to the same extent, if their bindings are correctly adjusted according to the ISO 11088 standard. However, compared to about $70 \%$ of males only one fifth of females in this study were able to self-release their ski bindings with both legs. Therefore, the question arises whether a lowering of the binding settings for females by, e.g. $15 \%$ would be relevant in order to decrease the risk of female knee injuries without an increase of inadvertent releases. However, to answer this question, more research in laboratory as well in field settings is needed. 
In conclusion, three times more females than males were unable to self-release their ski bindings although their bindings were correctly adjusted according to the ISO 11088 standard. In addition, females reached about 20\% lower RRT values within failure of binding release trials although males and females did not differ with regard to relative isometric leg strength.

Acknowledgement The author gratefully acknowledges support for this study from the University of Innsbruck (Doktoratsstipendium NEU). We also highly appreciate the help by Franz Patscheider for providing the Wintersteiger Speedtronic adjustment system in his ski rental shop.

\section{References}

1. Russel K, Christie J, Hagel BE (2010) The effects of helmets on the risk of head and neck injuries among skiers and snowboarders: a meta-analysis. CMAJ 182(4):333-340. doi:10.1503/ cmaj.091080

2. Cusimano MD, Kwok J (2010) The effectiveness of helmet wear in skiers and snowboarders: a systematic review. Br J Sports Med 44:781-786. doi:10.1136/bjsm.2009.070573

3. Ruedl G, Philippe M, Sommersacher R et al (2014) Current incidence of accidents on Austrian ski slopes. Sportverletz Sportschaden 28(4):183-187. doi:10.1055/s-0034-1385244

4. Burtscher M, Gatterer H, Flatz N et al (2008) Effects of modern ski equipment on the overall injury rate and the pattern of injury location in alpine skiing. Clin J Sport Med 18(4):355-357

5. Ekeland A, Rodven A (2011) Skiing and boarding injuries on Norwegian slopes during two winter seasons. In: Johnson RJ, Shealy JE, Senner V (eds) Skiing trauma and safety, 18th Volume. Journal of ASTM International 4:139-149. doi: 10.1520/JAI102817

6. Burtscher M, Sommersacher R, Ruedl G, et al (2009) Potential risk factors for knee injuries in alpine skiers. In: Johnson RJ, Shealy JE, Langran M (eds) Skiing trauma and safety, 17th Volume. Journal of ASTM International 6(1):73-76

7. Hewett TE, Meyer GD, Ford KR (2006) Anterior cruciate ligament injuries in female athletes: part 1, mechanisms and risk factors. Am J Sports Med 34:299-311

8. Ruedl G, Schranz A, Fink C et al (2009) Knee injuries in female recreational alpine skiing —an overview of risk factors and prevention. Deutsche Zeitschrift für Sportmedizin 60:345-349

9. Greenwald RM, Toelcke T (1997) Gender differences in alpine skiing injuries: a profile of the knee-injured skier. In: Johnson RJ, Mote CD, Ekeland A (eds) Skiing trauma and safety, 11th Volume. Journal of ASTM International, 111-121

10. LaPorte JD, Binet MH, Fenet N, et al (2009) Ski bindings and lower leg injuries, a case control study in Flaine, 2006. In: Johnson RJ, Shealy JE, Langran M (eds) Skiing trauma and safety, 17th Volume. Journal of ASTM International, 77-88

11. Ruedl G, Webhofer M, Linortner I, Schranz A, Fink C, Patterson C, Nachbauer W, Burtscher M (2011) ACL injury mechanisms and related factors in male and female carving skiers: a retrospective study. Int J Sports Med 32(10):801-806. doi:10.1055/s-0031-1279719

12. Ruedl G, Helle K, Tecklenburg K et al (2016) Factors associated with self-reported failure of binding release among ACL injured male and female recreational skiers: a catalyst to change ISO binding standards? Br J Sports Med 50:37-40. doi:10.1136/bjsports-2015-095482

13. Ruedl G, Sommersacher R, Woldrich T et al (2010) Mean speed of winter sport participants depending on various factors. Sportverletz Sportschaden 24:150-153

14. Werner S, Willis K (2002) Self-release of ski-binding. Int J Sports Med 23:530-535

15. Ekeland A, Holtmoen A, Lystad H (1993) Lower extremity equipment-related injuries in alpine recreational skiers. Am J Sports Med 21(2):201-205

16. Jørgensen U, Fredensborg T, Haraszuk JP et al (1998) Reduction of injuries in downhill skiing by use of an instructional ski-video: a prospective randomised intervention study. Knee Surg, Sports Traumatol Arthrosc 6(3):194-200 
17. Raschner C, Platzer HP, Patterson C et al (2012) The relationship between ACL injuries and physical fitness in young competitive ski racers: a 10-year longitudinal study. Br J Sports Med 46:1065-1071. doi:10.1136/bjsports-2012-091050

18. Scher IS, Mote CD (1999) Comparison of needed and recommended retention settings for snow skiing. In: Johnson R (ed) Skiing trauma and safety, 12th Volume. Journal of ASTM International, $107-119$

19. Shealy JE, Ettlinger CF, Johnson RJ (2005) How fast do winter sports participants travel on alpine slopes? In: Johnson RJ, Shealy JE, Ahlbäumer MG (eds) Skiing trauma and safety, 15th Volume. Journal of ASTM International, 59-66

20. Brunner F, Ruedl G, Kopp M et al (2015) Factors associated with the perception of speed among recreational skiers. PLoS One 10(6):e0132002. doi:10.1371/journal.pone.0132002. eCollection 2015

21. LaPorte JD, Binet MH, Fenet N, Constans D (2006) Ski bindings and lower leg injuries: a two year case-control study in Avoriaz. Abstracts of the sixteenth international symposium on ski trauma and skiing safety, Arai Mountain, Niigata, Japan, 17-23, April 2005. Knee Surg Sports Traumatol Arthrosc 14:100-101

22. Ettlinger CF, Johnson RJ, Shealy JE (2006) Functional and release characteristics of alpine ski equipment. Abstracts of the sixteenth international symposium on ski trauma and skiing safety, Arai Mountain, Niigata, Japan, 17-23 April 2005. Knee Surg Sports Traumatol Arthrosc 14:97-104

23. Senner V, Michel FI, Lehner S et al (2013) Technical possibilities for optimizing the skibinding-boot functional unit to reduce knee injuries in recreational alpine skiing. Sports Eng $16: 211-228$

24. Sinning WE (1985) Body composition and athletic performance. In: Clarke DH, Eckert HM (eds) Limits of human performance. The Academy Papers, Champaign, pp 45-56

Open Access This chapter is distributed under the terms of the Creative Commons AttributionNoncommercial 2.5 License (http://creativecommons.org/licenses/by-nc/2.5/) which permits any noncommercial use, distribution, and reproduction in any medium, provided the original author(s) and source are credited.

The images or other third party material in this chapter are included in the work's Creative Commons license, unless indicated otherwise in the credit line; if such material is not included in the work's Creative Commons license and the respective action is not permitted by statutory regulation, users will need to obtain permission from the license holder to duplicate, adapt or reproduce the material. 